\title{
O CARÁTER INSONDÁVEL DAS AÇÕES MORAIS EM KANT
}

Aguinaldo PAVÃO1

- RESUMO: À primeira vista, o que parece razoavelmente defensável na posição kantiana, com base na Fundamentação da Metafísica dos Costumes, é que as ações imorais são insondáveis, mas não o são como as ações morais. Estas são sempre insondáveis, aquelas quando vestem a conformidade ao dever, pois quando são contrárias ao dever são sondáveis. Mas na Crítica da Razão Pura (1980b, p.279, n.; B 579, n.80) Kant afirma que "a moralidade própria das ações (mérito e culpa), mesmo a de nosso próprio comportamento, permanece-nos totalmente oculta", pois não sabemos o quanto devemos imputar ao efeito puro da liberdade ou à simples natureza. Assim, ao que parece Kant defende duas posições. Uma, apregoando a insondabilidade parcial das ações imorais, outra uma opacidade total da qualidade moral das ações. Julgo, contudo, que, no fundo, Kant pode sustentar, sem cair em contradição, tanto a posição de que (a) as ações contrárias ao dever sinalizam a maldade de uma máxima como a tese de que (b) o mérito ou demérito moral jamais pode ser observado. A primeira alternativa é a que verificamos, por exemplo, na Fundamentação da Metafísica dos Costumes e que também na Religião desempenha um importante papel, uma vez que Kant tem de assumir, de algum modo, a experiência de ações más. Já a segunda tese parece ter um fundo eminentemente especulativo. Ela visa a mostrar a indecidibilidade metafísica acerca da qualidade moral de uma máxima.

- PALAVRAS-CHAVE: máxima, ação moral, mal moral, liberdade, insondabilidade.

1 Professor Adjunto do Departamento de Filosofia da Universidade Estadual de Londrina-UEL. Artigo recebido em out/06 e aprovado em abr/07. 
Para Kant, "chama-se [...] mau a um homem não porque pratique ações que são más (contrárias à lei), mas porque essas são tais que deixam inferir ${ }^{2}$ nele máximas más" (Kant, 1992, p.26; Kant, 1991d, p.666). Estabelecido que a maldade não consiste nas ações más, mas nas máximas más, surge o problema de saber como é possível identificar um homem mau. A experiência não é refratária à discriminação de ações más, pois dada a lei, uma ação a ela contrária, tem de ser classificada como má. É concedida à experiência a possibilidade de capturar a maldade de certas ações, mas não de poder nos fornecer um saber acerca da qualidade moral do agente.

Já na Crítica da Razão Pura encontramos a advertência de Kant

A moralidade própria das ações (mérito e culpa), mesmo a de nosso próprio comportamento, permanece-nos totalmente oculta. As nossas responsabilidades só podem ser referidas ao caráter empírico. Mas quanto disto se deve imputar ao efeito puro da liberdade, quanto à simples natureza e quanto ao defeito de temperamento do qual não se é culpado, ou à natureza feliz (merito fortunae) do mesmo, eis algo que ninguém pode perscrutar e conseqüentemente, também não julgar (richten) com toda a justiça. (Kant, 1980b, p.279, n.; B 579, n. 80)

É importante perceber que Kant não está dizendo apenas que não podemos julgar os outros, mas que também nós não temos poderes para julgar a nós mesmos. De fato, ele diz que "ninguém (niemand) [...] pode julgar com toda a justiça".

Ademais, Kant não diz que nós não sabemos se as ações são efeitos da liberdade ou da natureza. Kant afirma que nós não sabemos o quanto deve ser imputado à liberdade ou à natureza. ${ }^{3}$ Com essa afirmação não ocorre uma interdição total do juízo moral. A assertiva apenas restringe a sua acribia. Admitir que ninguém julga com toda a justiça não significa eliminar todo o julgamento. A tese parece simplesmente introduzir cláusulas de reservas quanto ao caráter peremptório do juízo moral.

E ainda, o que é mais importante aqui, ficando aberta a possibilidade de uma exposição empírica de ações que podem ser consideradas livres, é possível reconciliar essa passagem com a posição de que as ações más quer dizer, não eventos ou comportamentos que podem ser remetidos à patologias comportamentais - sinalizam a maldade do homem, ou seja, de que há visibilidade parcial das ações que caem sob um juízo moral.

Sua posição, contudo, é desenvolvida com mais clareza na Fundamentação da Metafísica dos Costumes. Embora, nesse livro, Kant tenha partido

2 A minha opção por "inferir" deve-se à sugestão do Prof. Marcos Lutz Müller (Unicamp). Artur Morão traduz schliessen por "incluir".

3 No original: "Wie viel aber davon reine Wirkung der Freiheit, wie viel der blossen Natur ..." (Kant, 1991a, p.501n; B 579 n). 
(I seção) do exame do uso comum (gemeinen Gebrauch) da razão prática e, com base nisso, extraído o conceito de dever, deve-se notar que tal estratégia de modo algum autoriza que se trate empiricamente o conceito de dever. ${ }^{4}$

\section{Na Fundamentação da Metafísica dos Costumes, Kant declara:}

Pelo contrário, quando atentamos na experiência humana de fazer ou deixar de fazer, encontramos queixas freqüentes e, como nós mesmos concedemos, justas, de que não podem apresentar nenhum exemplo seguro de intenção [Gesinnung] de agir por puro dever; porque, embora muitas das coisas que o dever ordena possam acontecer em conformidade com ele, é contudo ainda duvidoso que elas aconteçam verdadeiramente por dever e que tenham portanto valor moral. [...]

Na realidade, é absolutamente impossível encontrar na experiência com perfeita certeza um único caso em que a máxima de uma ação, de resto conforme ao dever, se tenha baseado puramente em motivos morais e na representação do dever. (Kant, 1980c, p.119)

De fato, a experiência é um lugar evanescente da liberdade e da imputabilidade moral.

Nenhum homem pode tornar-se consciente com toda a certeza de ter cumprido o seu dever de um modo inteiramente desinteressado, pois isso cabe à experiência interna, e para esta consciência do seu estado de alma seria preciso ter uma representação perfeitamente clara de todas as representações e de todas as considerações associadas ao conceito de dever mediante a imaginação, o hábito e a inclinação, representação essa que em nenhum caso se pode exigir. (Kant, 1988b, p.68) ${ }^{5}$

Naturalmente, uma vez admitida a existência de Deus, pode-se atribuir a este ser a capacidade de sondar nossas máximas. Para Kant, Deus "pers-

4 É isso que Kant textualmente apregoa: "Do fato de até agora havermos tirado o nosso conceito de dever do uso vulgar da nossa razão prática não se deve de forma alguma concluir que o tenhamos tratado como um conceito empírico" (1980c, p.119).

5 Portanto, nem o próprio agente sabe se age moralmente. Vale registrar que, nas Lições de Ética, datadas geralmente no início da década de 80, Kant acreditava que o indivíduo poderia saber se agiu moralmente. "As intenções morais dos outros só podem ser julgadas por Deus, se bem que cada um é um juiz competente em matéria de suas próprias intenções" (Kant, 1988a, p.277). Já nas Grandezas Negativas, um texto de 1763, Kant escreve algo aparentemente mais próximo, em comparação com as Lições de Ética, ao agnosticismo moral da Fundamentação da Metafísica dos Costumes. Ele diz: "é humanamente impossível deduzir de uma maneira certa o grau de intenção virtuosa do outro a partir de suas ações, e Aquele que vê no fundo dos corações reservou apenas para si esse julgamento". (Kant, 1980a, p.298). Digo próximo ao agnosticismo moral porque Kant fala, nas Grandezas Negativas, em graus. Ele admite, portanto, que eu possa saber sobre a existência de uma intenção virtuosa, não podendo saber apenas o seu grau. De todo modo, vale registrar, que Delbos viu nessa passagem (Kant, 1980a, p.298) a descoberta de Kant de que "o único princípio que permite qualificar a conduta humana" é a "intenção do sujeito agente" (Delbos, 1969, p.82). Reboul também vê aí um anúncio das formulações da Fundamentação Metafísica dos Costumes (cf. 1971, p.51). 
cruta o fundo inteligível do coração (de todas as máximas do arbítrio)" (Kant, 1992, p.54). Já o mesmo não ocorre com o ser humano, pois como declara Kant, "O juiz humano não pode perscrutar o interior dos outros homens" (Kant, 1992, p.102). Também podemos ler na Metafísica dos Costumes: “... não é possível ao homem penetrar de tal modo na profundidade de seu próprio coração que alguma vez pudesse estar completamente seguro de seu propósito moral e da limpeza de sua intenção, ainda que fosse numa ação; ainda quando não duvide de modo algum da legalidade da mesma" (Kant, 1994b, p.246). É lícito, assim, afirmar que Kant adota um agnosticismo em relação à real moralidade de nossas ações. Vale sublinhar que esse agnosticismo deve ser entendido como "um agnosticismo sobre nossas máximas" (Allison, 1990a, p.93).

É interessante destacar, ainda que marginalmente, que a defesa de Kant da opacidade irredutível das intenções, dá ensejo a uma crítica ao fanatismo moral. Na Crítica da Razão Prática, Kant afirma que

se o fanatismo (Schwärmerei), no significado mais geral, é a ultrapassagem empreendida segundo princípios dos limites da razão humana, então o fanatismo moral (moralische Schwärmerei) é esta ultrapassagem dos limites que a razão pura prática põe à humanidade, ao não permitir que se estabeleça o princípio subjetivo de determinação das ações conformes ao dever, isto é, o móbil moral das mesmas, em nada mais do que na própria lei. (Kant, 1986, p.101)

Quer dizer, segundo Kant, é apenas o respeito à lei introduzido nas máximas que vale como fundamento de determinação do agir moral para seres finitos como os homens. Não cabe, em se tratando da humanidade, nenhum devaneio com perfeições morais sonhadas, fundadas a partir de sentimentos, portanto empiricamente, de pretensão de pureza moral. Mediante o fanatismo moral, as pessoas são levadas ao ufanismo de uma pretensa disposição que, pela sua própria natureza, espontaneamente agiria de modo moral, sem precisar do respeito à lei (cf. Kant, 1986, p.100-101). Ora, a disposição moral manda observar a lei moral por dever. Sendo assim, cabe chamála de virtude. Isso implica dizer que a disposição moral é uma disposição "em luta" (im Kampfe), e não santa, pois não há como criaturas finitas estarem na "posse de uma plena pureza das disposições da vontade" (Kant, 1986, p.101). Ora, os ânimos caem em "simples fanatismo moral e intensificação da presunção" quando ilusoriamente acreditam que "o que constitui o princípio determinante de suas ações não seria [...] o respeito pela lei", mas o "puro mérito" (barer Verdienst) (Kant, 1986, p.101; Kant, 1991c, p.207). ${ }^{6}$

6 Na Religião, lemos: "A convicção de poder distinguir os efeitos da graça dos da natureza (da virtude), ou até de conseguir em si produzir os últimos é fanatismo (Schwärmerei)" (Kant, 1992, p.176). 
Uma objeção previsível à tese kantiana é a de que ela despreza certas ações, atestadas empiricamente, que poderiam ser consideradas morais. Nesse sentido, vale citar Schopenhauer.

É certo que há ações feitas por caridade desinteressada e por justiça espontânea. Referindo-me apenas à experiência e não aos fatos de consciência, são provas dessas últimas ações os casos isolados mas indubitáveis em que, não havendo nem perigo de perseguição legal nem também de descoberta e de qualquer suspeita, foi, não obstante, dado pelo pobre ao rico o que lhe pertencia. (Schopenhauer, 1995, p.108) ${ }^{7}$

Nowel-Smith (1966), por sua vez, pensou que poderia efetuar um colapso conceitual na argumentação kantiana sobre a insondabilidade de nossas ações morais. É verdade que ele não procura explicitamente esse fim, isto é, criticar especificamente a insondabilidade das ações morais. O seu objetivo é refutar a tese de que nossas ações, quando não praticadas por dever, são frutos do egoísmo e de que as ações que consideramos altruístas podem ser remetidas ao endereço de um egoísmo encoberto ou inconsciente. Vale, assim, verificar como Nowel-Smith constrói o seu argumento, cujo alvo é certamente Kant. Ele afirma que

o argumento habitualmente usado para mostrar que o altruísmo é egoísmo encoberto, quando não é altruísmo consciente, pode ser voltado contra o próprio caráter de consciente. Se somos levados a dizer que um homem que procura ajudar outros por genuíno desejo de proporcionar-lhes bem estar é, de fato, um egoísta disfarçado, que só quer satisfazer sua própria benevolência, por que não poderemos dizer que o homem que procura ajudar outros por senso de dever é, em verdade, um egoísta disfarçado que deseja satisfazer seu senso de dever? O argumento é tão absurdo num caso como no outro. (Nowel-Smith, 1966, p.132)

Ele acredita que o absurdo do primeiro caso consiste no fato de que, sendo o egoísmo, tal como ele entende, apenas a hostilidade ou indiferença em relação ao bem estar dos outros (cf. idem, p.132), não tem sentido sustentar que é fruto do egoísmo justamente aquela ação que visa ao bem estar alheio. O segundo contra-senso seria propriamente a redução ao absurdo da tese de que o que há de genuinamente moral é a ação desinteressada cujo

7 No Livre Arbítrio podemos ler: "a ação, com o motivo que a provocou, não é considerada senão como um testemunho do caráter de seu autor; ela é também, o mais seguro sintoma da sua moralidade" (Schopenhauer, 1925, p.101). É verdade que Schopenhauer demonstra em algumas passagens ter hesitado sobre esse ponto. Com efeito, é dele também a afirmação de que "infelizmente não se pode decidir a questão [do critério de reconhecimento das ações morais] de modo puramente empírico, porque, na experiência, sempre é dada apenas a ação, mas os impulsos não são evidentes" (Schopenhauer, 1995, p.122-123). 
móvel é o senso de dever, ${ }^{8}$ pois esta também não escaparia da suspeição que se lança às ações cujo móbil são as inclinações.

Ora, o que Nowel-Smith supõe ser um absurdo, em Kant, não é absurdo.

Acontece por vezes na verdade que, apesar do mais agudo exame de consciência, não possamos encontrar nada, fora do motivo moral do dever, que pudesse ser suficientemente forte para nos impelir a tal ou tal boa ação ou a tal grande sacrifício. Mas daqui não se pode concluir com segurança que não tenha sido um impulso secreto de amor-próprio [geheimer Antriebe der Selbstliebe], oculto sob a simples capa daquela idéia, a verdadeira causa determinante da vontade [bestimmende Ursache des Willens] Gostamos de lisonjear-nos então com um móbil mais nobre que falsamente nos arrogamos, mas em realidade, mesmo pelo exame mais esforçado, nunca podemos penetrar completamente até os móbiles secretos dos nossos atos, porque quando se fala de valor moral, não é das ações visíveis que se trata, mas dos seus princípios íntimos [innere Prinzipen] que não se vêem. (Kant, 1980c, p.119)

Deve-se ter cuidado aqui, pois a expressão "innere Prinzipen" não pode ser entendida como se significasse algum privilégio introspectivo. Para desenvolver esse ponto vale a pena retornar à Religião.

Embora Kant sustente que "não se podem observar as máximas, ${ }^{9}$ nem mesmo (nicht allemal) ${ }^{10}$ em si próprio, por conseguinte, o juízo de que o autor seja um homem mau não pode com segurança basear-se na experiência" (Kant, 1991d, p.666), Silber (1960) acredita que é possível que o agente saiba, ao menos às vezes, sob qual máxima está agindo.

Poder-se-ia alegar, a partir de Silber, que uma ação por dever se torna "visível" no mais íntimo perscrutar da consciência pelo próprio sujeito. Quer dizer, poder-se-ia supor a existência de uma experiência interna, via introspecção, que permitiria ao menos ao agente saber se sua ação é por dever.

Silber pensa que Kant sustenta serem os motivos das ações às vezes disponíveis ao próprio indivíduo no sentido interno (Silber, 1960, p.xcvi).

8 É preciso esclarecer que essa é a expressão que Nowel-Smith usa para a noção kantiana de ação por dever.

9 O que também fica claro em Crítica da Razão Prática (Kant, 1986, p.74), em que se encontra a declaração de que é a "máxima da vontade" (die Maxime des Willens) (Kant deveria ter dito máxima do arbítrio, mas na Crítica da Razão Prática persiste ainda um uso ambíguo dos termos Wille e Willkür) que determina o sentido do bem e do mal moral.

10 Se seguíssemos a tradução de Artur Morão, leríamos: "não se podem observar as máximas, nem sequer todas às vezes (nicht allemal) em si próprio", o que daria ensejo a perguntar se Kant estaria a supor que, às vezes, posso saber se estou agindo segundo determinada máxima? A interpretação de Silber parece pensar que caberia tal pergunta e que a mesma deveria ser respondida afirmativamente. 
Ele dá como abono Religião (Kant, 1992, p.26). ${ }^{11}$ Mas aí Kant não fala em nenhum momento que podemos saber quando agimos moralmente. Vale a pena citar a passagem em que Silber defende tão extravagante tese. "Mas os motivos atrás dos atos fenomênicos, isto é, as máximas sob as quais eles estão baseados, jamais podem ser observados por outros e são apenas às vezes aparentes ao próprio indivíduo no sentido interno" (Silber, 1960, p.xcvi). Silber volta à carga afirmando que "nós conhecemos moralmente a nós mesmos apenas como nos aparecemos a nós mesmos, [...] nós jamais podemos conhecer os motivos secretos do coração ou o caráter de nossas disposições exceto por um raciocínio indireto de nossas ações morais" (Kant, 1960, p.cii). ${ }^{12}$

Ora, a interpretação de Silber é de uma fragilidade básica. Ela compromete o agnosticismo kantiano sobre o conhecimento das ações morais. Além disso, se Kant diz que a experiência deve ser rejeitada como via de acesso ao saber sobre sob que máxima se age, ele também não poderia admitir, nem ao menos às vezes, ${ }^{13}$ que o agente possa saber (interpretando, assim, o "em si próprio"). Pois, o saber do agente seria, de todo modo, empírico, através da "observação" de seus estados mentais. Em suma, não posso concordar com a posição de Silber, pois defendo que a máxima que qualifica a maldade ou a bondade do arbítrio no acolhimento do móbil tem de ser entendida como uma máxima insondável, ainda que isso possa acarretar colisões pontuais com certas afirmações de Kant. ${ }^{14}$

Ademais, contra essa interpretação depõe claramente o próprio texto kantiano. Kant na Fundamentação da Metafísica dos Costumes (Kant, 1991b, p.34) expressamente sustenta o caráter insondável das ações morais. Kant defende, pois, uma posição claramente coerente com os princípios de sua filosofia crítica. Com efeito, esses princípios impedem qualquer acesso cognitivo aos objetos que não podem ser dados numa experiência possível, isto é, que não são disponíveis no espaço e no tempo.

A fim de sabermos se um homem é de fato mau, teríamos de poder sondar a máxima má da ação e, mais do que isso, o próprio fundamento da má-

11 Na edição da Religião que Silber faz a introdução, lemos: "but a man's maxims, sometimes even his own, are not observable" (p.16 da tradução de Theodore M. Greene e Hoyt H. Hudson). Isso parece um equívoco análogo ao cometido por Artur Morão. Pensar que Kant diz que "mas as máximas de um homem algumas vezes não são observáveis, nem para ele próprio", é descuidar do texto original e fundar uma interpretação num abono sem solidez.

12 A bem da verdade, esta segunda citação, conforme mostrarei mais adiante, não está totalmente errada.

13 Ver nota 12

14 Há dois possíveis sentidos de máxima em Kant. Um, que permitiria separar máxima do seu móbil, outro que tomaria os dois conceitos como intrinsecamente ligados. A minha posição se inclina em favor do segundo sentido. 
xima deveria nos ser de algum modo acessível. Ora, é por demais certo que a experiência não pode nos oferecer essas informações. Mas aqui surge um problema. Será que na Religião Kant defende uma visibilidade parcial do mal (portanto, a experiência discriminaria ações livres de ações causalmente determinadas). Ao que parece Kant defende a visibilidade parcial do mal (ver Kant, 1992, p.26). Se uma ação é má (contrária ao dever), então a máxima é má. Agora, se uma ação é boa (conforme o dever), não necessariamente a sua máxima será boa. Assim, "a ação má não pode encobrir uma intenção boa, ao passo que a significação de uma ação conforme a moral permanece moralmente ambígua" (Bruch, 1968, p.64).

Na Religião lemos:

No tocante à consonância das ações com a lei não há (pelo menos, não deve haver) diferença alguma entre um homem de bons costumes (bene moratus) e um homem moralmente bom (moraliter bonus); só que num as ações nem sempre, porventura nunca, têm a lei como único e supremo móbil, mas no outro a têm sempre. $\left(\right.$ Kant, 1992, p.36) ${ }^{15}$

Isso tudo está de acordo com a Fundamentação da Metafísica dos Costumes, em especial com os parágrafos 9 a 12 da I seção (cf. Kant, 1980c, p.112-114), em que Kant procura mostrar que o valor moral de uma ação consiste em que ela seja praticada por dever e não apenas conforme ao dever. Nestes parágrafos, Kant reconhece que é difícil a distinção quando uma ação é praticada conforme ao dever e, além disso, o sujeito é levado a ela por uma inclinação imediata (cf. Kant, 1980c, p.112).

De fato, para que seja possível, de algum modo, a qualificação de ações como imorais, é preciso admitir que a ação é livre, o que não está dado na experiência. Isso poderia levar a um impasse insolúvel. O empírico, embora sondável, não permite imputabilidade; o inteligível, que permite, é insondável. Mas Kant admite a existência de, digamos, "signos" da liberdade (cf. Reboul 1971: 154). Kant diz que o caráter empírico é o sinal sensível do caráter inteligível (Kant, 1980b, p.277; B 574). Ora, de algum modo, está a se admitir que o domínio da experiência serve para delimitarmos o campo do imputável do não imputável. Esse caso seria justamente aquele em que o

15 Por que Kant diz "não deve haver" diferença entre um homem de bons costumes e um homem moralmente bom? Com isso Kant sugere que pode haver diferença entre um homem bom (moralmente) e um homem apenas correto (legalmente). Por certo é possível pensar um homem correto que não seja bom. Mas o ponto é que Kant está a se referir à consonância das ações com a lei. Nesse caso, parece inconcebível uma diferenciação, pois do ponto de vista da legalidade eles estão no mesmo patamar. Uma vez que o escopo da presente discussão é fixar a tese do caráter insondável das ações morais, deixo esse problema, portanto, apenas registrado, como uma observação secundária. 
caráter empírico sinaliza ações de agentes racionais, isto é, de seres que agem com base em imperativos. ${ }^{16}$

De modo ilustrativo, podemos considerar o fato de que a experiência deve nos precaver que o sujeito a ser imputado não seja um louco. Nas Lições de Metafísica, Kant considera que a primeira infância e a loucura, incluindo nesta última estados psicológicos como uma melancolia extrema ou depressão, representam condições empíricas que nos levam a considerar um agente como não livre. ${ }^{17} \mathrm{Na}$ Crítica da Razão Prática, Kant afirma que a auto-acusação que o agente faz quando comete uma falta tem como restrição o fato de ele estar "no seu juízo, isto é, ... no uso da sua liberdade" (Kant, 1986, p.114). ${ }^{18}$ Quer dizer, não cabe imputar ao indivíduo que não tem consciência do que está fazendo. Conseqüentemente, pode-se dizer que certas ações podem ser computadas na receptividade da sensibilidade ${ }^{19}$ demarcando-se assim alguma fronteira entre o imputável e o não imputável, entre as ações livres e as não livres. Mas para isso, é preciso que nós não tenhamos razões para considerar estas ações, ações de um agente racional. Para ser imputável, o sujeito tem de ser capaz de compreender as exigências morais e poder, assim, fazer autêntico uso de sua liberdade.

A reflexão que acabo de fazer é congruente com a tese de Kant na $R e-$ ligião de que, não obstante ser impossível termos acesso à disposição, seja através da experiência externa ou da experiência interna, é cabível a admissão de uma inferência através da experiência externa, ainda que essa não possa jamais nos oferecer "estrita certeza" (cf. Kant, 1992, p.69). Kant admite aí, portanto, a possibilidade de inferências aproximadas de nossos motivos, não por uma observação interna de nossos princípios, mas sim pelas ações externamente observáveis. "Não avaliamos a nossa disposição de ânimo imediatamente, mas só segundo os nossos atos" (idem, p.82).

Deve-se assinalar ainda que o conhecimento de que somos morais não é possível porque só podemos ter conhecimento de fenômenos. Ora, se somos morais não o somos empiricamente, portanto, não podemos saber se somos morais. Por introspecção, que é autoconhecimento empírico, só po-

16 Veja a esse respeito em Ramos Esteves (2000, p.61). É preciso advertir que isso não implica afirmar um critério de decisão para discriminar ações livres de ações naturalmente determinadas. Jamais podemos saber se uma ação particular é resultado de uma causalidade livre ou causalidade natural, pois não temos um tal poder de conhecimento. Assim, a possibilidade de nos enganarmos ao atribuir a liberdade a uma certa ação nunca pode ser afastada.

17 Cf. I. Kant. Metaphisik L., edição da Academia, vol, 28, p.254-257, citado por Allison (1990 a, p.59 e 74).

18 Sobre esse ponto, ver também Allison (1990 a, p.59) e Reboul (1971, p.156).

19 Desse modo, a alegação de Kant de que a ação do homem "de modo algum pode ser computada na receptividade da sensibilidade" (1980b, p.2777; B 575), tem de ser lida como uma referência à ação no sentido forte, isto é, uma determinação racional. 
demos apontar causas que expliquem e não o fundamento capaz de justificar e imputar moralmente.

É correta, portanto, a afirmação segundo a qual "a introspecção, a 'experiência interior', é insuficiente para sondar as verdadeiras intenções de um indivíduo. O indivíduo pode bem conhecer as máximas que ele adota como suas, mas ele não conhecerá jamais o fundamento (Roviello, 1984, p.138)". ${ }^{20}$ Kant oportunamente adverte: "em nenhuma parte alguém se engana mais facilmente do que naquilo que favorece a boa opinião acerca de si mesmo" (Kant, 1992, p.74).

Enfim, embora alguns comentaristas de Kant, como Silber, por vezes, escorreguem a respeito do caráter insondável das ações morais, como argumentado acima, principalmente com base na Fundamentação da Metafísica dos Costumes, de modo algum podemos saber se agimos moralmente ou não.

De todo modo, é preciso reconhecer que a passagem da Religião (cf. Kant, 1992, p.26; 1991d, p.666) dá margens a leituras equivocadas. Vou retomar essa passagem, citando-a integralmente.

Chama-se, porém, mau a um homem não porque pratique ações que são más (contrárias à lei) (gesetzwidrige), mas porque essas são tais que deixam incluir nele máximas más. Ora, podem decerto observar-se pela experiência ações contrárias à lei, e também (pelo menos em si mesmas) com consciência contrárias à lei; mas não se podem observar suas máximas, nem sequer todas as vezes em si próprio, por conseguinte, o juízo de que o autor seja um homem mau não pode com segurança basear-se na experiência. (Kant, 1992, p.26; 1991d, p.666)

Mas se não podemos pensar uma ação má senão a partir de uma máxima má, este homem não teria também de ser considerado mau? Se Kant

20 Há, não obstante, um problema na afirmação de Roviello. Que o indivíduo possa conhecer as suas máximas, mas não o seu fundamento, é uma declaração que merece esclarecimentos. O que significa "fundamento" nesse contexto? Como vimos atrás, a máxima deve ser entendida, num sentido forte, como um princípio que exprime a motivação racional do agente, contendo, desse modo, o móbil da ação. Contudo, é possível entendermos a afirmação de Roviello. Para isso, basta tomarmos "máxima" num sentido fenomênico e "fundamento" como máxima no sentido numênico. Kant na Religião mesmo sugere essa diferenciação. Ao distinguir entre virtus phaenomenon - isto é, uma virtude conforme apenas à legalidade e suscetível de observação - e virtus noumenon - a verdadeira virtude moral em que o homem age segundo o móbil da moralidade -, ele declara: "O intento firme, feito prontidão, no seguimento do dever chama-se virtude, segundo a legalidade como seu caráter empírico (virtus phaenomenon). Tem pois a máxima persistente de ações conformes à lei" (Kant, 1992, p.53). Ainda sobre a virtude fenomênica, ele diz: "O homem acha-se virtuoso quando se sente consolidado em máximas de observância do seu dever" (1992, p.53). Como se percebe, é possível que o indivíduo conheça essas suas máximas da virtude fenomênica. Todavia, o fundamento, isto é, a máxima inteligível nunca poderá ser conhecida nem pelo próprio indivíduo. 
quer dizer que não é pela exterioridade que julgamos a qualidade moral de um homem, ele está certo e não é difícil aceitar sua tese. A questão é que uma parcela da exterioridade (ações contrárias ao dever) parece ser reveladora de uma má qualidade moral.

De fato, o problema não é a exterioridade da ação, mas sim a máxima. ${ }^{21}$ À primeira vista, o que parece razoavelmente defensável na posição kantiana, com base na Fundamentação da Metafísica dos Costumes, e talvez até com certo respaldo da Crítica da Razão Pura, é que as ações imorais são insondáveis, mas não o são como as ações morais. Estas são sempre insondáveis, aquelas quando vestem a conformidade ao dever, pois quando são contrárias são sondáveis. Todavia, realmente o trecho citado dá margem a mal-entendidos. De acordo com a passagem em tela, na Religião as coisas parecem ser diferentes. Kant teria mudado de posição? A passagem de $R e-$ ligião (cf. Kant, 1992, p.26; 1991d, p.666) parece justamente afirmar que também as ações imorais são insondáveis, quer sejam contrárias ou conforme ao dever. Ora, (a) se as ações são más, e isso é possível ser reconhecido pela experiência, as suas máximas também não são más? Ademais, (b) o que Kant está de fato querendo dizer quando afirma que algumas ações más não são ações de um homem mau?

No fundo, acredito que Kant pode manter as duas posições, isto é, de que (a) as ações contrárias ao dever sinalizam a maldade de uma máxima e que (b) uma máxima, como tal, nunca pode ser sondada com certeza. ${ }^{22} \mathrm{~A}$ primeira alternativa é a que verificamos, por exemplo, na Fundamentação da Metafísica dos Costumes e que também na Religião desempenhará um papel importante, pois Kant tem de assumir, de algum modo, a experiência de ações más. Já a segunda tese tem um fundo eminentemente especulativo. Ela visa a mostrar a indecidibilidade última acerca da qualidade moral de uma máxima. Conseqüentemente, pode-se sustentar que inferências aproximativas de uma ação contrária à lei para uma máxima imoral são possíveis, sendo, contudo, impossível fazer uma inferência estrita da ação para a máxima.

21 O comentário desse tópico permite que se corrija um equívoco. Esse equívoco consiste em pensar que "ações em conformidade com o dever não transgridem a lei moral, ainda que não sejam feitas em razão dele. Elas não são ações incorretas, elas são a maneira correta de agir, embora praticadas por errôneas razões" (Walker, 1999, p.20). Ora, uma ação conforme ao dever pode perfeitamente transgredir a lei moral. Com efeito, se ela for praticada não por dever, mas com base numa máxima que tome as inclinações como móbiles da ação ela fere a lei moral. É precisamente isso que Kant, no prefácio da Fundamentação da Metafísica dos Costumes, afirma. Ele diz que o princípio imoral também pode estar nas ações conforme ao dever (cf. Kant, 1980c, p.105). Portanto, nesse ponto, acredito que Walker erra.

22 São possíveis apenas inferências aproximadas. 
PAVÃO, Aguinaldo. The insondable character of moral actions on Kant. Trans/Form/ Ação, (São Paulo), v.30(1), 2007, p.101-113.

- ABSTRACT: We may say, on the basis of the Groundwork, that the moral actions are always unfathomable and that the immoral actions are unfathomable just when dress the conformity to the duty, therefore when they are contrary to the duty are fathomable. But in the Critique of Pure Reason (B 579) Kant affirms that "the real morality of actions, their merit or guilt, even that of our own conduct, thus remains entirely hidden from us". Therefore do not we know how much is ascribable to the pure effect of freedom or to the simple nature. Thus, Kant looks defends two positions. One, proclaiming that immoral actions are partially unfathomable, another a total obscurity of the moral quality of the actions. I judge, however, that, at bottom, Kant can maintain, without fall in contradiction, that (a) the contrary actions to the duty signal the wickedness of a maxim and that (b) the moral merit or moral unworthy can never be observed. To first alternative is assumed by Kant to account for experience of immoral actions (cf. Religion). The second thesis looks to have an eminently speculative bottom. It aims to show that moral quality of a maxim is undecidable metaphysically.

- KEYWORDS: maxim, moral action, moral evil, freedom, unfathomable.

\section{Referências bibliográficas}

ALLISON, Henry (1990a): Kant's Theory of Freedom. New York: Cambridge University Press.

BONACCINI, J. A. (2004): "Podemos censurar moralmente os outros? Metacrítica, Lisboa, Portugal, v.3, n.5, p.1-10, 2004.

BRUCH, J. L (1968): La Philosophie Religieuse de Kant. Paris: Aubier.

DELBOS, Victor (1969): La Philosophie Pratique de Kant. Paris: PUF.

ESTEVES, J. C. Ramos (2000) "Kant tinha de compatibilizar natureza e liberdade no interior da filosofia crítica? Studia kantiana 2(1), p.53-70.

KANT, Immanuel (1980a): "Essai pour introduire en philosophie le concept de grandeurs négatives". Tradução de Jean Ferrari. In: Oevures philosophiques. Vol. I. Ed. Ferdinand Alquié. Paris: Gallimard, p.251-302.

(1991a): Kritik der reinen Vernunft. Werkausgabe III/IV. Ed. W. Weischedel. Frankfurt: Suhrkamp.

(1994): Crítica da Razão Pura. Tradução de Manuela Pinto dos Santos e Alexandre Fradique Morujão. Lisboa: Calouste Gulbenkian.

(1980b): Crítica da Razão Pura. Tradução de Valério Rohden e Udo Baldur Moosburguer. São Paulo: Abril Cultural.

(1988a): Lecciones de Ética. Tradução de Roberto Rodriguez Aramayo e Concha Roldan Panadero. Barcelona: Crítica. 
KANT, Immanuel (1991b): Grundlegung zur Metaphysik der Sitten, Werkausgabe VII. Ed. W. Weischedel. Frankfurt: Surkamp.

(1980c): Fundamentação da Metafísica dos Costumes. Tradução de Paulo Quintela. São Paulo: Abril Cultural.

(1991c): Kritik der praktischen Vernunft. Werkausgabe VII. Ed. W. Weischedel. Frankfurt: Surkamp.

(1986): Crítica da Razão Prática. Tradução de Artur Morão. Lisboa: Ed. 70.

(1991d): Die Religion innerhalb der Grenzen der blossen Vernunft. Werkausgabe VIII. Ed. W. Weischedel. Frankfurt: Surkamp.

(1980d): A Religião dentro dos limites da simples razão. Tradução de Tânia Maria Bernkopf. São Paulo: Abril Cultural.

(1992): A Religião nos limites da simples razão: Tradução de Artur Morão. Lisboa: Ed. 70.

(1988b): "Sobre a expressão corrente: isto pode ser correcto na teoria, mas nada vale na prática". In: A paz perpétua e outros opúsculos. Tradução de Artur Morão. Lisboa: Ed. 70, p.57-102.

(1991e): Die Metaphysik der Sitten. Werkausgabe VIII. Ed. W. Weischedel. Frankfurt: Surkamp.

(1994): La Metafísica de las Costumbres. (Prólogo e introdução geral) Tradução de Adela Cortina Orts e Jesus Conill Sancho. Madrid: Tecnos.

NOWEL-SMITH, p.H (1966). Ética. Tradução de Leonidas Hegenberg e Octanny S. da Mota. São Paulo: Bestseller.

REBOUL, Olivier (1971): Kant et le problème du mal. Montreal. PUM.

ROVIELLO, Anne-Marie (1984): L'instituition kantienne de la liberté. Bruxelles: Ousia.

SCHOPENHAUER, Arthur (1925): Essai sur le Libre Arbitre. Tradução de Salomon Reinach. Paris: Félix Alcan.

(1995): Sobre o Fundamento da Moral. Tradução de Maria Lúcia Cacciola. São Paulo: Marins Fontes.

SILBER, John (1960). "The ethical significance of Kant's religion". In: Religion within the Limits of Reason Alone. Tradução de T. M. Greene e H. H. Hudson. New York: Harper e Brothers, p.lxxix-cxxxiv.

WALKER, Ralph (1999): Kant: Kant e a lei moral. Tradução de Oswaldo Giacóia Junior. São Paulo: Ed. Unesp. 